\title{
SYSTEM PRINCIPLES IN ANALYSIS OF LARGE-SCALE PROJECTS (ON THE EXAMPLE OF HIGH-SPEED TRAFFIC PROJECTS)
}

\author{
Alina T. Romanova ${ }^{1, *}$, Alexander A. Vygnanov ${ }^{2}$, Maria A. Vygnanova ${ }^{3}$ \\ ${ }^{1}$ Russian University of Transport, Obrazcova 9-9, 127994 Moscow, Russia, email: tribenerg@gmail.com \\ ${ }^{2}$ Russian University of Transport, Obrazcova 9-9, 127994 Moscow, Russia, email: vygnanov@miit.ru \\ ${ }^{3}$ Russian University of Transport, Obrazcova 9-9, 127994 Moscow, Russia, email: vygnanov@miit.ru \\ * Corresponding author
}

Reviewed positively: 08.05 .2020

Information about quoting an article:

Romanova A.T., Vygnanov A.A., Vygnanova M.A. (2020). System principles in analysis of large-scale projects (on the example of high-speed traffic projects). Journal of civil engineering and transport. 2(2), 91-97, ISSN 2658-1698,

e-ISSN 2658-2120, DOI: 10.24136/tren.2020.007

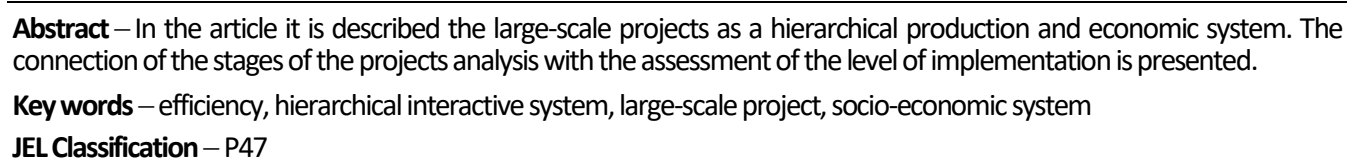

\section{INTRODUCTION}

The article presents the relationship of the main indicators for assessing the level of implementation of the principles of the system.

Large-scale projects - (LSP) influence many subsystems of national economy, and in some cases - regions of world economy. The effect of the LSP is multi-dimensional and changes the environment, which in turn affects the implementation and effects of the project and its development. An important function is project management, which is a hierarchical structure in which pro-duction and socio-economic processes take place.

\section{THE KEY CONCEPT}

The key concept in the theory of systems and the defining property of any system is its integrity [1], that is, the generation of only its characteristic functions and features.

Each element is considered only in its relationship with other elements of the system. The combined work of heterogeneous and interrelated elements provides qualitatively new functional properties of the whole. This integrity is characteristic of all socio-economic systems (SES).

It is important to understand the integrity of a system in the context of its relationships with other systems or with the broader system of which it is a part. These systems determine the environment. A holistic system is relatively independent of the environment. This means that the system responds to environmental exposure, evolves due to this exposure, but retains the qualitative certainty and properties that distinguish it from other systems [2-3].

An essential characteristic of a holistic system is its structure. When you study a system as a model the structure acts as a way to describe its organisation. Depending on the task of the study elements are identified, and their relationships and essential connections to the problem being solved are reflected. At the same time structuring of the system is determined by its internal properties. The elements of the system are selected by the researcher depending on the purposes of the analysis.

If the investigated system is a real object, there is impossibility of versions of its description, [4-6].

Taking into account the above, it is preferably to hierarchical representation of the system structure in the form of interconnected subsystems, which in turn, they are shared into lower-level elements and so on. The depth of hierarchical shapes is determined by the objectives of the study. 
The structure is dynamic. It's evolution in time, and space reflects the development of the system $[2,5]$.

Integrity, structure, element, hierarchy, level of interaction with the external environment are the most common concepts and are inherent in systems of any nature.

The internal source of self-development is the continuous process of creating and resolving contradictions. Contradictions are determined by the diversity of cultures and economic patterns, the interests of social groups and individuals, and the forms of material and spiritual life.

Purposeful self-organisation of the system in practice implements the capacity for selfdevelopment.

One of the main functions of self-organisation is to maintain its qualitative certainty, that is, the stability of the system as a whole, during the evolution of the system. The adaptive capabilities of the system are primarily aimed at maintaining stability.

However, the stable system is constantly in a state of dynamic equilibrium. It fluctuates continuously with respect to the equilibrium position. This is a condition for the continuous emergence of contradictions as driving forces of its evolution.

\section{CHARACTERISTIC OF SOCIO-ECONOMIC SYSTEMS} (SES)

Stability of SES is provided by elements of selforganisation such as differentiation and lability.

The properties of SES may include:

- Fundamental uncertainty in the development of SES;

- Incomplete observability of SES operation processes;

- Late information on the processes of interest to us.

The main problems of information support for decision-making in SES are laid down in these properties.

The functioning and development of any socioeconomic system take place in competition with other SES.

The system responds to changes in the relevant environment with an adaptation mechanism.

Organisational systems form a special form of SES. When analysing control problems in these systems, coordinating, control and actuating elements are identified [4-5].

Strict control by any criterion in SES is impossible. It is contrary to the essence of these systems. However, the concept of criterion is useful. The criterion refers to some function characterising the state of the system and the degree of achievement of the purpose of its functioning in each certain period of time.

The decomposition of goals in time and space according to the organisational structure of the system forms a hierarchical system of tasks. Decision-making processes within hierarchical management systems of socio-economic organisations have specific features:

- Most decisions are taken in situations not previously met (political, social or economic repetition is unlikely):

- The choice of solutions is usually made in conditions of high uncertain-ty;

- Decisions made under severe time constraints. The content of decisions is significantly influenced by the personal qualities and interests of decision makers. However, the interests of different links in the management hierarchy may not be the same.

Solutions are classified by degree of uncertainty of initial information. Distinguish between structured, poorly structured, and unstructured solutions.

In the management of socio-economic organisations, there are generally mixed situations with one or the other prevailing. Also mixed situations form the main class of weakly structured solutions.

\section{Principle Of Systemic ANAlysis}

The practical orientation of systemic research can be presented as a fundamental principle of systemic analysis - a principle of purpose. This principle is that any complex object should be considered only from the perspective of solving a certain task. The description of the system should be targeted. The target de-fines the method and form of the object description. The purpose of the analysis dictates the selection of generalisation on which the description of the system is built.

The second principle is the principle of "simplicity" and the requirement to save assumptions in evidence. The goal principle can be understood as cut-ting off everything stuck in a targeted description of the system.

From the above-mentioned properties of any system follows the principle of multilevel description. This means that any object must be described:

- as part of the broader system;

- as a holistic phenomenon; 
- as some complex structure whose internal structure needs to be analysed in order to achieve the objectives of the study.

The minimum required number of levels of description of the system is three. In fact, a significantly larger number of levels of description are typically introduced in the SES study.

In system analysis of SES, the number of description levels is deter-mined by the objectives and the depth of analysis required to achieve them.

Description levels require the concept of system languages. Each level of presentation of the system has a description language.

Thus, the description of the SES should be structured to reflect:

- Objectives and objectives of the study;

- The place of the system under study in the wider system, the degree of dependence on the environment, the shape and mechanism of this dependence;

- main parameters of system functioning;

- system structure and functional function of elements;

- content of information links;

- structure of management and organisation of targeted behaviour of the system;

- goals of the system, decomposition of goals into tasks;

- hypothesis on the mechanism of system functioning;

- analysis of the functioning and forecasting of the development of the system based on the identified goals and objectives of the system and its functioning mechanism.

All this should be contained in each level of the system description.

\section{THE RATIONALE FOR THE FEASIBILITY OF LARGE-SCALE PROJECTS}

The rationale for the feasibility of large-scale projects is in the following stages:

- Evaluation of project efficiency at the level of national economy, industry, budget of the country;

- The value of the integrated project efficiency indicator is generated, on the basis of which the ranking and selection of projects are carried out. This phase reflects the principle of partnership and corporate integrity. The first reflects the harmonisation of the project elements and the interests of external market participants. The second - ensures mutually beneficial cooperation of all participants of the project, including socioeconomic institutions in order to optimise the development of society. From the point of view of large systems analysis, this reflects the principles of system integrity and targeting. These principles are also reflected through the harmonisation of interests of project participants, which determines the financial model of the project. In addition, the principle of complex systems, such as the principle of compromise, is taken into account in the formation of factors of importance of interests of different business entities participating in the project and in the construction of the criterion [5]. At the next stage, the organisational and resource conditions for the implementation of the project selected by the performance indicators are determined. Work is planned in time and space with appropriate resource constraints and allocation. The use of these principles and their harmonisation in accordance with the strategic goals of the participants and phases of the life project is shown on the example of solving the problem of developing the capacities of transport engineering enterprises during the implementation of HST projects [6-8].

Railway transport meets the transport needs of enterprises and the population. One of the most important tasks of transport is to increase the level of satisfaction of passengers with the services of the transport complex [5-7]. Factors determining the dynamics of passenger traffic are factors of social stability, including the degree of social inequality of passengers, inflation, unemployment rate, macroeconomic, intra-industry and intertransport factors, including the level of competition between modes of transport and modes of transport process in passenger traffic. The article proposes an algorithm for estimating the necessary increase in capacity of transport engineering enterprises in the long term on the basis of the forecast of passenger traffic change.

The features of projects in railway transport is defined the following:

a) the unity of railway network, which defines the borders investment project;

b) a significant share of railway transport in the provision of transportation needs of the state, legal entities and individuals, works and services, and, consequently, the interest of the state and legal entities in the development of railway transport;

c) insufficient application of the law on concession Contracts agreements, which leads to risks already at the stage of agreements on cooperation in the implementation of projects;

d) scale of investment projects in the railway 
sector transport by the amount of resources consumed and by the impact on the environment, as well as GDP.

To the organization's criteria of high-speed traffic $-(\mathrm{HST})$ includes the following:

- security;

- dependence on weather conditions;

- the impact on the environment;

- price flexibility;

- services on the way;

- logistics and seat reservations;

- emotional comfort;

- physiological comfort;

- protection from terrorist threats;

- insurance;

- total trip time.

In this case, the economic features of the operation of the HST are as follows:

- Improving the mobility of passengers and retention them time, the increase in passenger traffic and the creation of new flights.

- Increasing the level of comfort and security (compared to other mode).

- The Association of large cities and promotion the development national economy.

- Agglomeration of improving ties between the administrative centers and peripheral areas, which leads to a more dynamic development of lagging regions.

- Formation of new multimodal transport systems together with air services, commuter trains and public transport urban transport.

- Development of environmentally friendly transport.

- Increasing the socio-economic potential of th country.

- Professional development and employment level populations.

- Tourism development.

- Increasing the prestige of Railways and the state.

As a rule, these questions are worked out at the assessment stage the economic effects of the creation of the HST.

Traditional economic assessments of projects take into account mostly direct effects, but for high-speed development projects passenger traffic in the country, the crucial role played by external General economic effect.

The effectiveness analysis should be carried out not only for individual.

HST projects, but also on a network-wide scale, taking into account system effects from the development of high-speed and high-speed traffic.
Distinguish between direct and external effects of the development of lines HST:

1. Direct:

Direct effects for rail transport:

- additional revenue from increased traffic or reduced unit costs of transportation costs;

- reducing the need for investment in bridging bottlenecks on freight lines through the creation of high-speed lines HST;

- optimization of the infrastructure load level;

- increased line load due to hub (combined route) schemes of transportation of passengers to stations;

- allocation of specialized lines for heavy trucks trains.

Multimodal effects:

- optimization of the geography of cargo and passenger transport taking into account competitiveness of different types of transport;

- optimization of subsidies for passenger transportation in different types transport's;

- unloading of the road network in agglomerations;

- creation of multi-modal hubs by supplying passenger railway line.

2. External:

- the growth of output in connection with the debottlenecking of the network;

- growth of budget revenues;

- increase the connectivity of urban agglomerations (increase in wages, employment, investment and productivity);

- growth of interregional trade;

- investment growth;

- reduction of transport costs (based on the General transport model balances)

- growth of investment and innovation demand from railway transport;

- integration into the world economy through the development of cargo transit;

- reducing environmental damage and improving safety;

- improving the comfort of passenger transport. As an approach to the calculation of external effects from the creation of HSM the estimation of time saved was used:

- tourists - 4.46 ( $\mathrm{f}$ people per hour);

- transit passengers - 5.04 (f people per hour);

- travel passengers - 39.96 (f per hour), [5-7]; Results of the study of effects on the experience of foreign operation of HSM it can be argued that the HSM is a source of economic growth regions.

At the same time as the development of highspeed traffic (HST), it is necessary to form capacities 
for the production of rolling stock for HST at domestic enterprises of transport engineering.

\section{THE ENLARGED ALGORITHM}

The enlarged algorithm for forecasting the necessary development of production capacities of transport engineering enterprises for the production of high-speed rolling stock includes the following units:

Unit 1 - forecasting of population growth in the regions where HSR sections pass in the long term. The forecast of passenger traffic of high-speed communication in the direction was carried out in an overall manner, with the assumption of linear dependence of passenger traffic on the change in the population of the region. It is known that construction of the high-speed railways - HSR is effective for regions which have values of the index of economic development.

Promising transport corridors for the development of high-speed traffic are defined by a number of criteria:

- Large population of the area of gravity (more than 3 million persons);

- High population density (57.26 persons per square $\mathrm{km}$ );

- A large proportion of the urban (more mobiles) population;

- Availability of stable passenger traffic. In addition, the change is due to redistribution of passenger traffic between types transports.

Unit 2 - calculation of passenger traffic forecast with taking into ac-count expert assessments. The forecast takes into account:

1. change in passenger traffic due to change population size.

2. determination of the importance of these or those consumer requirements in each segment of the branch market on the basis of a matrix of pair comparisons;

3. characteristic of the consumer properties which are implemented in the service made by the company during implementation of the HSR project;

4. formation of reference characteristics of services by the rival companies in the branch market;

5. assessment of level of competitiveness of the service realized by each company on each segment of the branch market;

6. definition of a relative deviation between the level of competitiveness of service which the company for this segment of consumers implementing the investment project and the competitiveness level which is provided by this or that company for the same segment of consumers can provide;

7. determination of total size of relative change of consumer demand for products/service which the company can provide for each segment of consumers. The calculation is based on the relative deviation between the level of competitiveness of the service and the levels of competitiveness that other companies provide. These calculations and results are obtained in block 6.

The total value of relative change in consumer demand is determined taking into account the share of each segment of consumers of the industry market;

8. determination of new level of demand on service of the company implementing the project in the results received in block 7 and of forecasts of demand for each segment of consumers in the absence of the project.

The forecast for consumer segments can be based on retrospective data for each of them or on scenario estimates.

Structure of the algorithm is shown in Figure 1. The following are descriptions of the analytical filling of the algorithm blocks in relation to the forecast estimate of passenger traffic at the HST [6].

1 block sets out the consumer requirements of different consumer groups - segments. By way of example, consumers are divided into 6 groups denoted a, b, c, d, e, f:

a) passengers of high-speed highways;

b) passengers with their own car;

c) passengers of public transport;

d) passengers of air transport;

e) low-mobility passengers;

f) high-speed rail passengers.

Systems of passenger requirements to travel characteristics are formed.

Block 2 uses paired comparison matrices, which determine the significance of an indicator from the consumer requirements system for the consumer of each group. Expert evaluations for each group are checked for consistency.

Block 3 defines the consumer requirements implemented on the HSR for passengers of each group. The comparison is based on the previously listed indicators of consumer requirements. At the same time, the question is asked to what extent the requirement of the corresponding group of passengers is fulfilled during transportation to the HSR. 


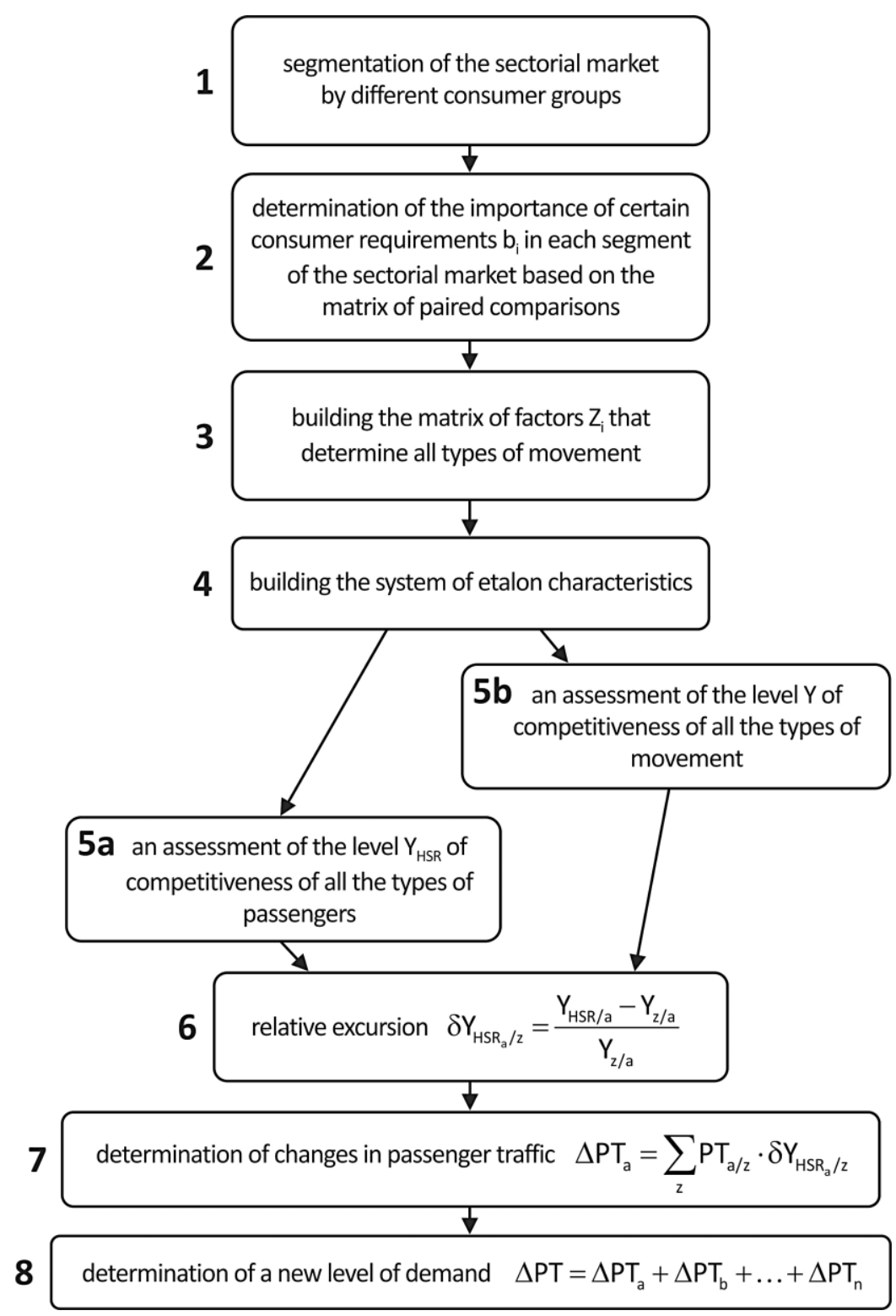

\section{Fig. 1. Structure of the algorithm}

Block 4 forms consumer properties sold in such types of passenger transport as high-speed traffic on railway transport, road transport on public and personal transport, and air transport. A population group belonging to the "slow-moving group" has been introduced, which includes people with physical restrictions and low wealth [6].
In block 5, the level of competitiveness of passenger transportation by HSR is estimated from the positions of each group of consumers $-Y_{B C M} / a$,

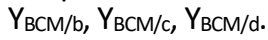

In addition, the competitiveness of each type of transport service, which we will designate $z$, for each group of passengers in the transport market 
system is assessed. This level of competitiveness is denoted $Y_{z / a}, Y_{z / b}, Y_{z / c}, Y_{z / d}$.

Block 6 - Estimate the relative deviation between the level of competitiveness of the HST of each group of passengers and the level of competitive-ness of other types of traffic for the same groups.

In the block 7, a possible outflow of passenger traffic from the corresponding group on the HSR section is generated. Its evaluation can be obtained as a sum of the products of passenger flows of the respective groups on the relative changes in the competitiveness of this movement.

Block 8 defines passenger traffic that may appear on the HST as a result of complex satisfaction of passenger demand for all groups of passengers.

Unit 3 - estimation of necessary capacity increase of transport enterprises. The assessment is based on the calculation of labour intensity of manufacturing a unit of high-speed rolling stock and the general labor intensity of works on production of high-speed trains for the predicted passenger traffic at the HSR.

\section{CONCLUSIONS}

The following conclusions can be made:

- The LSP affect many subsystems and in some cases - on the development of international regions;

- The effect from the LSP is multinational and develops in time, which changes the environment of the project and the conditions of its implementation;

- The depth of the economic analysis in each case should be determined in the relation to the project in accordance with the purpose and objectives of the company's development;

- Feedback between the project and the environment determines the nature of the proposed algorithm for analysis of the effectiveness of LSP;

- Proposed algorithm of LSP analysis based on basic principles of system analysis;

- The algorithm includes project analysis at different hierarchy levels;

- The multiplicity of possible solutions and the use of weight estimates for each reflects the interactive nature of the analysis system.

\section{ZASADY SYSTEMOWE W ANALIZIE WIELKOSKALOWYCH PROJEKTÓW INWESTYCYJNYCH \\ (NA PRZYKŁADZIE REALIZACII PROJEKTÓW W SYSTEMACH KOLEI DUŻYCH PRĘDKOŚCI)}

W artykule opisano projekty na dużą skalę jako hierarchiczny system produkcji. Przedstawiono powiązanie etapów analizy projektów z oceną poziomu realizacji.

Słowa kluczowe: hierarchiczny system interaktywny, projekt na dużą skalę, system społeczno-gospodarczy, wydajność

\section{REFERENCES}

[1] Luhman N. (2014). Book Review, Introduction to Systems Theory, International Journal of Systems and Society, 1(1), January-June 2014, ISBN: 978-0-7456-4572-8, pp. 55-57, www.igi-global.com/pdf.aspx?tid\%3D94651\%26ptid\%3D858 58\%26ctid\%3D17\%26t\%3Dintroduction+to+systems+theory (access date: 16/06/2020)

[2] Chikere, Cornell C., Nwoka J. (2015) "The Systems Theory of Management in Modern Day Organizations - A Study of Aldgate Congress Resort Limited Port Harcourt", International Journal of Scientific and Research Publications (IJSRP), Vol 5, Issue 9, September 2015, ISSN 2250-3153, pp. 1-7, www.ijsrp.org/research-paper-0915/ijsrp-p4554.pdf laccess date: $16 / 06 / 2020)$

[3] Бурков В.Н., Коргин Н.А., Новиков Д. А. (2009) Введение в теорию управления организационными системами. Либроком, 264 с., ISBN 978-5-397-00411-4. (In English: Burkov V.N., Korgin N.A., Novikov D.A. (2009) Introduction to the theory of management of organizational systems. Publisher: Librocom, 264 p., ISBN 978-5-397-00411-4).

[4] Новиков Д.А. (2012) Теория управления организационными системами Физматлит, 604 с., ISBN 978-5-94052-139-8. (In English: Novikov D.A., (2012) Theory of management of organizational systems. Publisher: Fizmatlit, 604 p., ISBN 9785-94052-139-8).

[5] Романова А.Т Выгнанов А.А (2018) Социальноэкономическая эффективность ВСМ-проектов. Учебное пособие, УМЦ ЖДТ, 314 с., ISBN 978-5-906938-63-3. (In English: Romanova A.T., Vygnanov A.A. (2018) Socio-economic efficiency of high-speed projects. Textbook, 2018. UMTSZhDT, 314 p., ISBN 978-5-906938-63-3)

[6] Романова А.Т., Попова М.В. (2016) Оценка общественной эффективности крупных инвестиционных проектов. Транспортное дело России. №2. С. 22-25., ISSN 2072-8689. (In English: Romanova A.T., Popova M.V. (2016) Assessment of the public effectiveness of large investment projects. Transport business of Russia. No2. ISSN 2072-8689, pp. 22-25)

[7] Bonnafous A., Crozet Y. (2014) "Efficiency indicators of Railways in France". International Transport Forum, France, Lyon, November 2014, 25 p., www.itf-oecd.org/sites/default/ files/docs/bonnafous-crozet-presentation.pdf (access date: 16/06/2020)

[8] Ross Davies. (2019) The EU's high-speed rail network dilemma, https://rail.nridigital.com/future_rail_oct18/slow_trains_the eu_s_high-speed_rail_network_dilemma 